\title{
Surface State Change of Lithium Metal Anode in Full Cell during Long Term Cycles
}

\section{Motoko NAGASAKI, ${ }^{a}, *$ Takuya MASUDA, ${ }^{b}$ Kei NISHIKAWA, $^{c}$ and Kiyoshi KANAMURA ${ }^{a}$}

a Department of Applied Chemistry for Environment, Graduate School of Urban Environmental Sciences, Tokyo Metropolitan University, 1-1 Minami-Ohsawa, Hachioji, Tokyo 192-0397, Japan

${ }^{\mathrm{b}}$ Research Center for Advanced Materials and Characterization, National Institute for Materials Science, Ibaraki 305-0044, Japan

c Center for GREEN Research on Energy and Environmental Materials, National Institute for Materials Science, Ibaraki 305-0044, Japan

*Corresponding author: mnagasaki@inorg777.apchem.ues.tmu.ac.jp

\begin{abstract}
In order to investigate the surface state change of the lithium metal anode during long term cycles, a laminate-type lithium metal rechargeable battery was fabricated from a lithium foil, a $\mathrm{Li}_{4} \mathrm{Mn}_{5} \mathrm{O}_{12}$ electrode, a polyimide (PI) membrane having a three-dimensionally ordered macroporous structure (3DOM) and a $1 \mathrm{~mol} \mathrm{dm}^{-3} \mathrm{LiPF}_{6}$ ethylene carbonate (EC) solution as an anode, a cathode, a separator and an electrolyte, respectively. After the charge/ discharge cycles, the chemical composition at the surface of the lithium metal anode taken from the laminate cell was investigated by X-ray photoelectron spectroscopy (XPS). Decomposition products of electrolyte, e.g. Licontaining organic compounds, $\mathrm{LiF}$ or $-\mathrm{PO}_{4}$ were accumulated on the lithium metal surface during long-term charge/discharge cycles. The accumulation of the decomposition products causes the increase of the lithium ion transport resistance of the battery, resulting in the inhibition of dissolution and deposition of lithium which is associated with drop of capacity.
\end{abstract}

(c) The Electrochemical Society of Japan, All rights reserved.

Keywords: Lithium Metal Rechargeable Battery, Lithium Metal Film, Laminate Cell, X-ray Photoelectron Spectroscopy

\section{Introduction}

A lithium metal is an ideal anode material for high-energydensity batteries because it has the most negative electrochemical potential and the lowest density among all the metals. It has been practically used as an anode material in a lithium primary battery. However, it is hardly used in rechargeable batteries owing to the formation of dendritic lithium during the charging process. A part of the dendritic lithium can be disconnected from the anode (so-called dead lithium metal), resulting in the degradation of charge/discharge characteristics. Therefore, intercalation type materials such as graphite, which can insert and extract lithium ions in and from its host structure reversibly, have been used in current lithium ion batteries. If a lithium metal anode can be used in rechargeable batteries without the host materials (such as graphite or $\mathrm{Si}$ ), a dramatic improvement of energy density can be accomplished.

In the case of the lithium ion rechargeable batteries, it is believed that a very stable film so-called Solid Electrolyte Interphase (SEI) is formed at the interface between a graphite anode and an organic electrolyte, resulting from the electrochemical decompositions of solution species such as a solvent and a lithium salt in a few initial charge/discharge cycles. ${ }^{1,2}$ The SEI film is stably retained at the surface of the host structure of graphite particles even after lithium ions are extracted completely. As a result, excessive decomposition can be effectively avoided by the SEI while it does not interfere the transport of lithium ions to the anode surface. In the case of the lithium metal rechargeable batteries, however, decomposition reactions of the electrolyte occur simultaneously with the electrodeposition of fresh lithium at the anode surface and the lithium ions are extracted from (through) those skin layers upon the charging process, resulting in the accumulation of a polymeric film consisting of those decomposed fragments at the interface between the newly electrodeposited lithium and the electrolyte. ${ }^{3,4}$ It is reported that the film is broken down upon the discharging process and formed again by surface reactions of the freshly bare metallic lithium with the electrolyte solution species during the dissolution of lithium., Thus, the formation process and role of the film at the lithium metal anode is more complicated than the SEI film at the graphite anode. In addition, it is reported that the morphology and chemical composition of the film significantly affect the morphology of electrodeposited lithium. ${ }^{6-8}$ For example, non-uniform distribution of the film thickness may cause the concentration of current density, resulting in the promotion of dendrites formation. Accordingly, understanding of the morphology and chemical composition of those films is a key for the improvement of the cycle performance. Although tremendous efforts have been dedicated to the surface analysis of lithium metal films as a model of the anode, ${ }^{6-12}$ most of works have been carried out as model systems such as beaker cells, coin-type cells or lithium metal symmetric cells in which a lack of electrolyte or a change of inner pressure of cell during charge/ discharge cycles can be ignored. However, it is very important to investigate the lithium metal surface under degradation conditions similar to the commercially available cell with long-term charge/ discharge cycles.

In previous works, we have developed materials suitable for lithium metal rechargeable batteries in order to improve the cycle performance. An ultrafine porous polyimide (PI) membrane with three-dimensionally ordered macroporous (3DOM) structure ${ }^{13-17}$ has a high porosity of ca. $70 \%$, and an ethylene carbonate (EC) solution (the best electrolyte for lithium metal) which can hardly permeate into a commercially available polyolefin separator, but can easily permeate into a 3DOM PI membrane (Figs. S1 and S2 in Supporting Information (SI)). A spinel-type $\mathrm{Li}_{4} \mathrm{Mn}_{5} \mathrm{O}_{12}$ cathode material ${ }^{18,19}$ can insert lithium ions in its host structure upon the 
initial discharging process and the electrochemical cycles can start from the dissolution reaction of lithium metal anode ${ }^{20,21}$ resulting in the improvement of the cycle performance owing to uniform surface of the anode (Fig. S3 in SI).

In the present work, the surface of the lithium metal anode is analyzed by X-ray photoelectron spectroscopy (XPS) in order to investigate the surface state change of the lithium metal anode during long-term charge/discharge cycles by using a laminate-type full cell composed of a lithium foil with copper current collector, $\mathrm{Li}_{4} \mathrm{Mn}_{5} \mathrm{O}_{12}$ electrode, 3DOM PI membrane and a $1 \mathrm{~mol} \mathrm{dm}^{-3} \mathrm{LiPF}_{6}$ EC solution as an anode, a cathode, a separator and an electrolyte, respectively.

\section{Experimental}

\subsection{Preparation of $\mathrm{Li}_{4} \mathrm{Mn}_{5} \mathrm{O}_{12}$ electrode}

$\mathrm{Li}_{4} \mathrm{Mn}_{5} \mathrm{O}_{12}$ was synthesized by Toshima Manufacturing Co., Ltd. on the basis of recipe as written below. A precursor was prepared by mixing fine powder of $\mathrm{Li}_{2} \mathrm{CO}_{3}$ and $\mathrm{Mn}_{3} \mathrm{O}_{4}$ with 4:5 in molar ratio and then baked at $500^{\circ} \mathrm{C}$ for 15 hours under $\mathrm{O}_{2}$ atmosphere. Slurry containing $80 \mathrm{wt} . \% \quad \mathrm{Li}_{4} \mathrm{Mn}_{5} \mathrm{O}_{12}$ as an active material, $10 \mathrm{wt} . \%$ acetylene black as a conductive agent, and $10 \mathrm{wt} . \%$ polyvinylidene fluoride (PVdF) as a binder in $N$-methylpyrrolidone (NMP) solvent was uniformly coated onto an aluminum foil as a current collector and dried in vacuum at $120^{\circ} \mathrm{C}$ for 12 hours. The thickness and the density of the electrode were $24 \mu \mathrm{m}$ and $1.8 \mathrm{~g} \mathrm{~cm}^{-3}$, respectively.

\subsection{Preparation of 3DOM PI separator}

A PI membrane was prepared by colloidal crystal templating method on the basis of the previous report. ${ }^{22}$ Slurry containing polyamic acid (JFE Chemical Corporation) and spherical silica particles with $300 \mathrm{~nm}$ diameter (SEAHOSTAR KE-P30, Nippon Shokubai Co., Ltd.) in a solvent of dimethyl acetamide was uniformly coated onto a glass plate and dried at $60^{\circ} \mathrm{C}$. Subsequently, a resulting light yellow sheet was heated at $320^{\circ} \mathrm{C}$ to convert the polyamic acid precursor to PI and then immersed in a $10 \mathrm{wt} . \% \mathrm{HF}$ aqueous solution at room temperature for 5 hours to eliminate the silica particles. PI membrane having 3DOM structure was obtained after the elimination of silica particles. The thickness of the membrane was about $30 \mu \mathrm{m}$.

\subsection{Assembly of laminate cells}

Laminate cells were assembled in a purified Ar-filled glove box as below. The $\mathrm{Li}_{4} \mathrm{Mn}_{5} \mathrm{O}_{12}$ electrode was used as a cathode and the lithium foil (thickness of $20 \mu \mathrm{m}$ ) adhered to the copper foil (thickness of $10 \mu \mathrm{m}$ ) (Honjo metal Co., Ltd.) was used as an anode. The areas of the cathode and the anode were 12.0 and $13.4 \mathrm{~cm}^{2}$, respectively. The ratio of capacity between the cathode and the anode was designed to be $1: 10$. The 3 DOM PI membrane dried in vacuum at $120^{\circ} \mathrm{C}$ for 24 hours was used as a separator. The electrolyte solution was $1 \mathrm{~mol} \mathrm{dm}^{-3} \mathrm{LiPF}_{6}$ in EC (Kishida chemical Co., Ltd.). The volume of the electrolyte was $600 \mu \mathrm{L}$. The water and HF contents in the electrolyte were less than $4 \mathrm{ppm}$ and $20 \mathrm{ppm}$, respectively.

\subsection{Electrochemical measurements}

The charge/discharge cycle performance of the laminate cells was measured at $30^{\circ} \mathrm{C}$ by using a charge/discharge unit (HJ1001SM8A, Hokuto Denko Corp.). At first, the cells were discharged from the open-circuit potential to $2.0 \mathrm{~V}$ at a constant current. Subsequently, the cells were charged to $3.7 \mathrm{~V}$ at a constant current and maintained at $3.7 \mathrm{~V}$ until the current decreased to $1 / 10$ of the constant current. The first three cycles were performed at $0.1 \mathrm{C}$ rate as an initial conditioning, and then at $1 \mathrm{C}$ rate for the cycle performance test. $\mathrm{C}$ rate was calculated based on an assumption that the theoretical capacity of $\mathrm{Li}_{4} \mathrm{Mn}_{5} \mathrm{O}_{12}$ used as a cathode material was $160 \mathrm{mAh} \mathrm{g}^{-1}$.
Electrochemical impedance spectroscopy was carried out in the frequency range of $100 \mathrm{kHz}-10 \mathrm{mHz}$ and an alternating current (AC) amplitude of $10 \mathrm{mV}$ at $30^{\circ} \mathrm{C}$ by using a potentiostat galnanostat (1287, Solartron) and a frequency response analyzer (1255B, Solartron) system after charging process.

\subsection{XPS analysis of lithium metal anodes}

After the charge/discharge cycles, the lithium metal anodes were extracted from the cells and washed with dimethyl carbonate (DMC). These samples were sealed in a transfer vessel (ULVACPHI) in a purified Ar-filled glove box, and transferred to the analysis chamber of the XPS equipment without air exposure to minimize any possible side reactions of the surface in open air. To compare a non-cycled anode with the cycled anodes, a lithium metal anode kept in the laminate cell without charge/discharge cycles for 8 days which was the same duration as 100 cycles at $1 \mathrm{C}$ was extracted as a reference sample.

The chemical composition of the lithium metal anode surface were investigated by using the XPS (Versa Probe II, ULVAC-PHI, Inc.) equipped with $\mathrm{Al}-\mathrm{K}_{\alpha}(1486.6 \mathrm{eV}) \mathrm{X}$-ray source (operating at $25 \mathrm{~W}$ and $15 \mathrm{kV}$ ) without argon ion sputtering. The spectra were collected at a pass energy of $46.950 \mathrm{eV}$ and a take-off angle (the angle between the sample surface and the analysis axis) of $60^{\circ}$. The spot diameter of X-rays was ca. $100 \mu \mathrm{m}$. In order to avoid the surface charging due to the emission of photoelectrons, charge compensation was performed using an electron neutralizer and an ion gun. In this study, charge up of samples was successfully compensated by this treatment. Previous reports mostly did not employ this treatment. Spectral fitting was carried out by using the fitting program (XPSPEAK 4.1). Peaks were assigned based on the references ${ }^{6,9,23-29}$ after subtracting the Shirley type baseline and correcting the background.

\section{Results and Discussion}

Figures 1(1) and (2) show charge and discharge curves at 1st, 100th, 200th, 300th and 400th cycle and cycle performance of cell with the deposit-dissolution efficiency of the anode against cycle
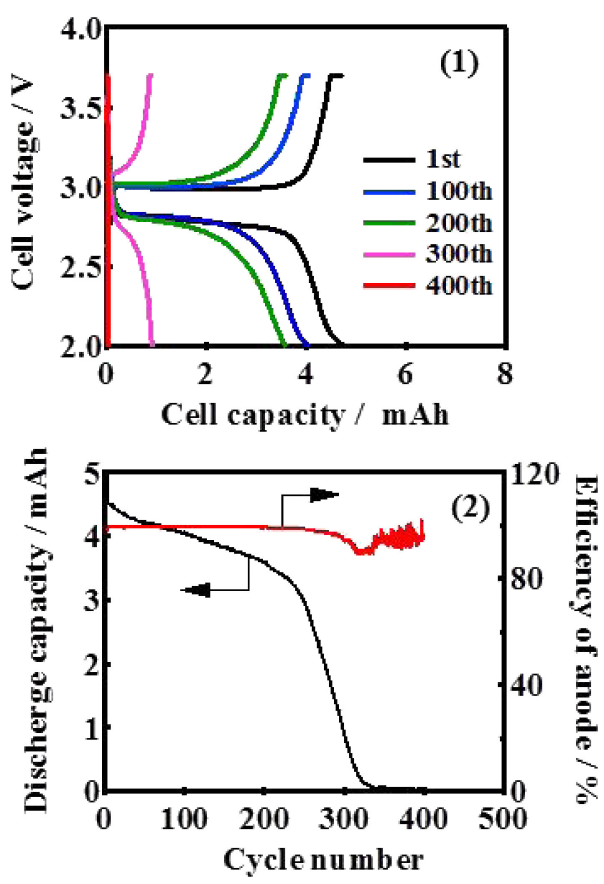

Figure 1. (1) Charge and discharge curves at 1st, 100th, 200th, 300th and 400th cycle, (2) cycle performance of cell with the deposit-dissolution efficiency of the anode against cycle number. 


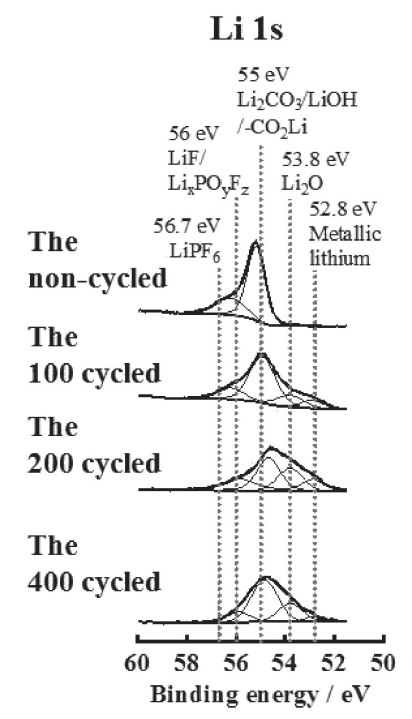

\section{1s}

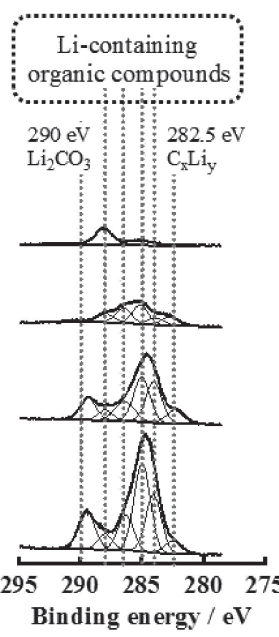

P 2p

F 1s

$687.5 \mathrm{eV}$

$\mathrm{LiPF}_{6} / \mathrm{Li}_{\mathrm{x}} \mathrm{PO}_{\mathrm{y}} \mathrm{F}_{\mathrm{z}}$

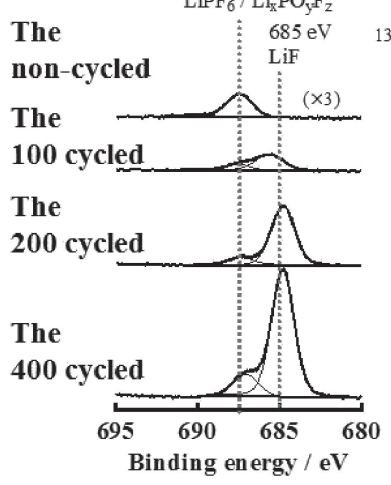

$136 \mathrm{eV}$

$\mathrm{Li}_{x} \mathrm{PO}_{\mathrm{y}} \mathrm{F}_{z} \quad 128.6$

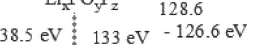

$133 \mathrm{eV}-126.6 \mathrm{eV}$
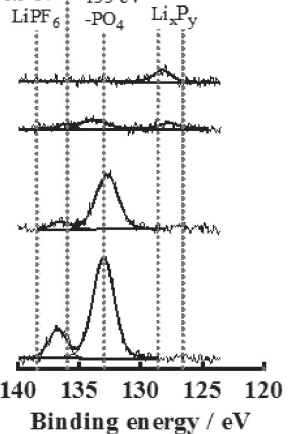

O 1s

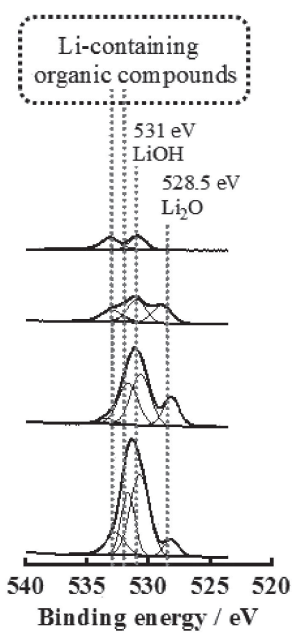

Figure 2. The XPS spectra in the Li 1s, C 1s, O 1s, F 1s, and P 2p regions of the anodes extracted from the non-cycled, 100 cycled, 200 cycled and 400 cycled cells.

number, respectively, confirming that discharge capacity of cell decreased gradually until 200 cycles and dropped suddenly after 200 cycles and the deposit-dissolution efficiency of the anode maintained approximately $99.5 \%$ until 200 cycles and decreased after 200 cycles. Various factors including the deterioration of the anode and the cathode are considered as the reasons for the deterioration of the cycle performance (Figs. S4 and S5 in SI). The main purpose in this study is to investigate the cause of deterioration of lithium metal rechargeable batteries, so that the surface state change of the anode was investigated at each stage of deterioration.

Figure 2 shows XPS spectra in the $\mathrm{Li} 1 \mathrm{~s}, \mathrm{C} 1 \mathrm{~s}, \mathrm{O} 1 \mathrm{~s}, \mathrm{~F} 1 \mathrm{~s}$, and $\mathrm{P} 2 \mathrm{p}$ regions of the anodes extracted from the non-cycled, 100 cycled, 200 cycled and 400 cycled cells. The surface composition of chemical species was estimated from the peak integrations of the XPS spectra by using the following equation. ${ }^{24,30}$

$$
\mathrm{C}_{\mathrm{x}}=\left(I_{\mathrm{x}} / \mathrm{S}_{\mathrm{x}}\right) /\left(\Sigma I_{\mathrm{i}} / \mathrm{S}_{\mathrm{i}}\right)
$$

where $C_{x}, I_{x}$ and $S_{x}$ are the fraction, integrated intensity and atomic sensitivity factor of any constituent $x$, respectively. Figure 3 shows the fractions of chemical species observed in each core level spectrum together with the capacity retention of the cell against cycle number.

At the non-cycled anode, peaks corresponding to $\mathrm{LiPF}_{6}, \mathrm{LiF} /$ $\mathrm{Li}_{x} \mathrm{PO}_{y} \mathrm{~F}_{z}$, and $\mathrm{Li}_{2} \mathrm{CO}_{3} / \mathrm{LiOH} /-\mathrm{CO}_{2} \mathrm{Li}$ are observed at $56.7 \mathrm{eV}, 56 \mathrm{eV}$ and $55 \mathrm{eV}$, respectively, showing that the lithium foil is covered with a film consisting of $\mathrm{LiOH}$ and $\mathrm{Li}_{2} \mathrm{CO}_{3}$ because metallic lithium is very reactive even with a trace amount of water and/or carbon dioxide in the production atmosphere. ${ }^{6}$ A small peak attributable to
$\mathrm{LiPF}_{6} / \mathrm{Li}_{x} \mathrm{PO}_{y} \mathrm{~F}_{z}$ in the $\mathrm{F} 1 \mathrm{~s}$ region $(687.5 \mathrm{eV})$ is considered to be $\mathrm{LiPF}_{6}, \mathrm{PF}_{5}$ or $\mathrm{POF}_{3}$. The mechanism of reaction between water and $\mathrm{LiPF}_{6}$ in an organic electrolyte solution was studied by Aurbach et al. ${ }^{31}$ and Hider et al. ${ }^{32}$ and the following equations were reported:

$$
\begin{aligned}
& \mathrm{LiPF}_{6} \rightleftarrows \mathrm{LiF}+\mathrm{PF}_{5} \\
& \mathrm{PF}_{5}+\mathrm{H}_{2} \mathrm{O} \rightarrow \mathrm{POF}_{3}+2 \mathrm{HF} \\
& \mathrm{LiPF}_{6}+\mathrm{H}_{2} \mathrm{O} \rightarrow 2 \mathrm{HF}+\mathrm{LiF}+\mathrm{POF}_{3}
\end{aligned}
$$

A shoulder peak observed in the $\mathrm{Li} 1 \mathrm{~s}$ region is attributable to $\mathrm{LiPF}_{6}$ $(56.7 \mathrm{eV})$ and $/$ or $\mathrm{LiF} / \mathrm{Li}_{x} \mathrm{PO}_{y} \mathrm{~F}_{z}(56 \mathrm{eV})$. A peak corresponding to $\mathrm{LiF}$ in the $\mathrm{F} 1 \mathrm{~s}$ region is not observed, suggesting that the reactions (1-3) hardly occur. Thus, the shoulder peak at about $56.7-56 \mathrm{eV}$ in the $\mathrm{Li} 1 \mathrm{~s}$ region and the peak at $687.5 \mathrm{eV}$ in the $\mathrm{F} 1 \mathrm{~s}$ region are probably derived from only $\mathrm{LiPF}_{6}$. Previously, it has been reported that a $\mathrm{LiF}$ film is formed at a lithium foil surface by the reaction (3) when it is immersed in a huge amount of $\mathrm{LiPF}_{6}$-based organic electrolyte solution (water content $10 \mathrm{ppm}$ or less) in a beaker cell. ${ }^{6}$ Unfortunately, this condition is completely different from a practical cell in which a minimum amount of electrolyte is injected. In this case, no peak due to $\mathrm{LiF}$ is observed in the $\mathrm{F} 1 \mathrm{~s}$ region. This is due to the fact that the amount of electrolyte is small and the water content of the electrolyte is very low (4 ppm or less). In addition, LiF generated by the equilibrium reaction (1) in a solution hardly remains on the electrode surface. This is very important fact to understand the SEI on lithium metal anode. Small peaks observed at $288 \mathrm{eV}$ (e.g. R$\left.\mathrm{CH}_{2} \mathrm{OLi}\right)$ and $285 \mathrm{eV}\left(-\mathrm{CH}_{2}-\mathrm{CH}_{2}-\right)$ in the $\mathrm{C} 1 \mathrm{~s}$ regions and observed at $533 \mathrm{eV}$ (e.g. $\left.\mathrm{R}-\mathrm{CH}_{2} \mathrm{OLi}\right)$ and $531 \mathrm{eV}(\mathrm{LiOH})$ in the $\mathrm{O} 1 \mathrm{~s}$ regions, suggesting a presence of small amount of organic compounds. For 


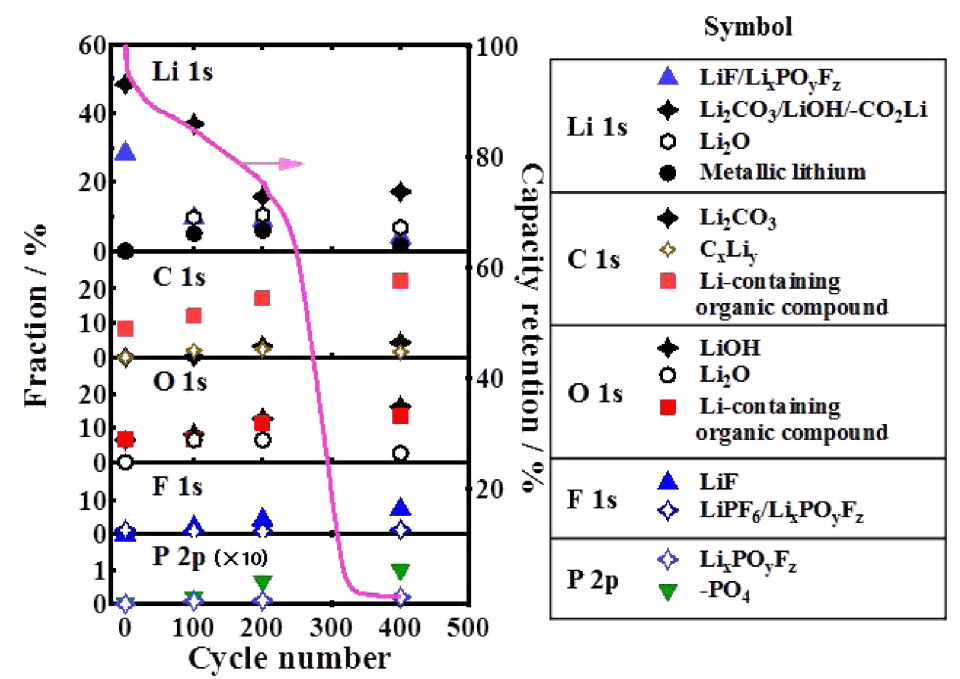

Figure 3. The fractions of the chemical species observed in each core level spectrum together with the capacity retention of the cell against cycle number.

example, $\mathrm{R}-\mathrm{OLi}$ has been reported as a reduction product of DMC. ${ }^{33,34}$ In the $\mathrm{P} 2 \mathrm{p}$ region, a peak corresponding to $\mathrm{Li}_{x} \mathrm{P}_{y}$ is observed at $128.6 \mathrm{eV}$. Although a binding energy of $\mathrm{Li}_{x} \mathrm{P}_{y}$ in the $\mathrm{Li} 1 \mathrm{~s}$ region is unknown, the peak can be overlapped with other species or too small to be detected. Thus, the major species at the non-cycled anode are $\mathrm{Li}_{2} \mathrm{CO}_{3} / \mathrm{LiOH}$, and small amount of species derived from the solvent and $\mathrm{LiPF}_{6}$ exist at the surface.

At the surface of the 100 cycled anode, peaks corresponding to metallic lithium ( $\mathrm{Li} 1 \mathrm{~s}, 52.8 \mathrm{eV}$ ), $\mathrm{Li}_{2} \mathrm{O}(\mathrm{Li} 1 \mathrm{~s}$ and $\mathrm{O} 1 \mathrm{~s}, 53.8 \mathrm{eV}$ and $528.5 \mathrm{eV}), \mathrm{C}-\mathrm{O}-\mathrm{C}(\mathrm{C} 1 \mathrm{~s}$ and $\mathrm{O} 1 \mathrm{~s}, 286.5 \mathrm{eV}$ and $533 \mathrm{eV}),-\mathrm{CLi}$ (C $1 \mathrm{~s}, 283.5 \mathrm{eV}), \mathrm{C}_{x} \mathrm{Li}_{y}(\mathrm{C} 1 \mathrm{~s}, 282.5 \mathrm{eV}),-\mathrm{CO}_{2} \mathrm{Li}(\mathrm{Li} 1 \mathrm{~s}, \mathrm{C} 1 \mathrm{~s}$ and $\mathrm{O} 1 \mathrm{~s}, 55 \mathrm{eV}, 290-291 \mathrm{eV}$ and $532 \mathrm{eV}$ ), LiF (Li $1 \mathrm{~s}$ and $\mathrm{F} 1 \mathrm{~s}, 56 \mathrm{eV}$ and $685 \mathrm{eV})$, and $-\mathrm{PO}_{4}(\mathrm{P} 2 \mathrm{p}, 133 \mathrm{eV})$ are observed in addition to the chemical species observed at the non-cycled anode. Although the peak corresponding to metallic lithium $(52.8 \mathrm{eV})$ is not observed at the non-cycled anode probably due to the formation of a relatively thick film consisting of $\mathrm{Li}_{2} \mathrm{CO}_{3}$ or $\mathrm{LiOH}$, it is observed at the 100 cycled anode, confirming the electrodeposition of fresh metallic lithium. This is coincident with the fact that the surface was measured after the end of the charging process, namely, after completion of the electrodeposit of lithium. Appearance of $\mathrm{Li}_{2} \mathrm{O}$ implies the occurrence of reactions of electrodeposited lithium with solvent, and $\mathrm{LiF}$ and $\mathrm{Li}_{x} \mathrm{PO}_{y} \mathrm{~F}_{z}$ are formed by the reaction (1-3) as previously described. It is considered that the organic compounds are derived from the products generated by the decomposition reactions of the solvent. For example, $\mathrm{Li}_{2} \mathrm{CO}_{3},\left(\mathrm{CH}_{2} \mathrm{OCOOLi}\right)_{2},{ }^{35,36}$ oligo-ester carbonate and PEO oligomer ${ }^{37,38}$ have been reported as decomposition products of EC. In the present work, these organic compounds generated by decomposition reactions of electrolyte are called as the Li-containing organic compounds. The reason for lack of the peaks corresponding to $\mathrm{Li}_{2} \mathrm{O}, \mathrm{LiF}$ and $\mathrm{Li}$-containing organic compounds at the non-cycled sample and their existence at the 100 cycled sample is due to the difference of the reactivity of Li species; Lithium surface is passivated by $\mathrm{Li}_{2} \mathrm{CO}_{3}$ and $\mathrm{LiOH}$ at the non-cycled sample while electrodeposited lithium is extremely reactive at the 100 cycled sample. So, the side reactions occur at the interface between the electrodeposited lithium and electrolyte in the course of electrodeposition, and electrodeposited lithium is covered with a new film. When the lithium metal dissolves during the following discharge process, a part of the film generated from those irreversible side reactions remains at the surface of the anode. The formation of a new film accompanying with electrodeposition of lithium and electrochemical dissolution of the electrodeposited lithium are repeated at each cycle. As a result, the films formed repeatedly in 100 cycles are accumulated on the surface of the 100 cycled anode. The state of the outermost surface is considered to be observed in XPS measurement.

At the surface of the 200 cycled anode, a significant change is observed in the XPS spectra. The intensity of the series of peaks corresponding to Li-containing organic compounds ( $\mathrm{C}$ 1s and $\mathrm{O} 1 \mathrm{~s}$ ), $\mathrm{LiF}(\mathrm{F} 1 \mathrm{~s}, 685 \mathrm{eV})$ and $-\mathrm{PO}_{4}(\mathrm{P} 2 \mathrm{p}, 133 \mathrm{eV})$ increased. Cell capacity began to deteriorate with the increase of these peaks after 200 cycles, suggesting that accumulation of the films is the main cause of the deterioration.

At the 400 cycled anode, the peaks derived from the same chemical species as the 200 cycled sample are observed and their fractions are changed further. In Fig. 3, it is confirmed that the fractions of the chemical species derived from the decomposition products such as Li-containing organic compounds, $\mathrm{LiF}$ and $-\mathrm{PO}_{4}$ increased with increasing cycle numbers. From these results, it can be said that the residue of remained films consisting of the decomposition products is accumulated on the surface of the anode (Fig. S6 in SI). The organic compounds containing a large amount of $\mathrm{C}$ and $\mathrm{O}$ elements are nonconductors, and the film or the layer containing such matters on the surface of the anode can increase the interfacial resistance in the cell and also the lithium ion transport resistance. As a result, the electrodeposition and dissolution reactions of lithium are inhibited and the deterioration is caused.

Figure 4 shows (1) Nyquist plots and (2) magnified Nyquist plots of the laminate cell at open circuit voltage around $3.2 \mathrm{~V}$ after charging process at 100th, 200th and 400th cycle, respectively. At all the spectra, semicircles or collapsed semicircles are observed in the high frequency region of $>100 \mathrm{~Hz}$, indicating charge transfer through the surface film formed on the anode and cathode. ${ }^{39,40}$ The resistance derived from these films increased with increasing cycle numbers. In the low frequency region, which is considered to be related to the solid state diffusion of lithium ion in the electrode bulk, ${ }^{41}$ a linear line at 100 th cycle changes into a part of collapsed semicircle at 400th cycle, indicating that the lithium ion diffusion is gradually inhibited with increasing cycle numbers. Since the impedance measurement was carried out by the full cell, resistances derived from the cathode and the anode appeared in the same spectrum. It was confirmed that the resistance in the low frequency region measured by using the 400 cycled full cell was larger than that measured by using a half cell of the 400 cycled cathode (Fig. S7 in SI). Therefore, the increase of the resistance with increasing cycle numbers in the low frequency region observed in Fig. 4 indicates that lithium ion diffusion is inhibited by the accumulation of the films consisting of the decomposition products on the anode. These results are in good agreement with the XPS results. 
(1)

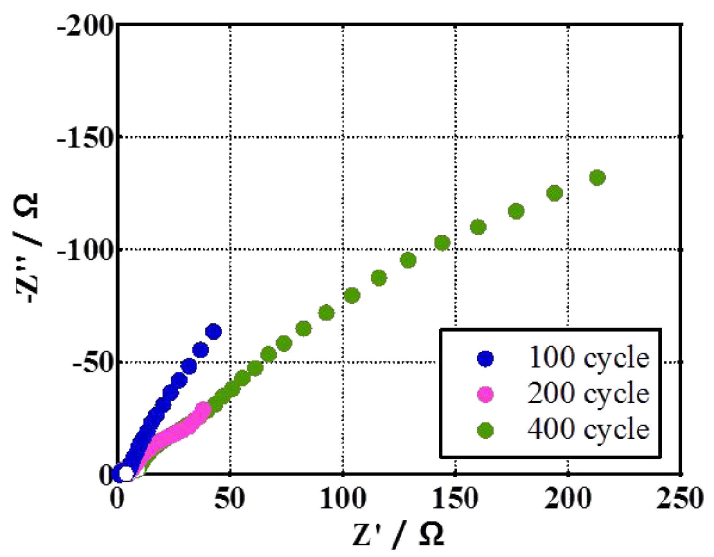

(2)

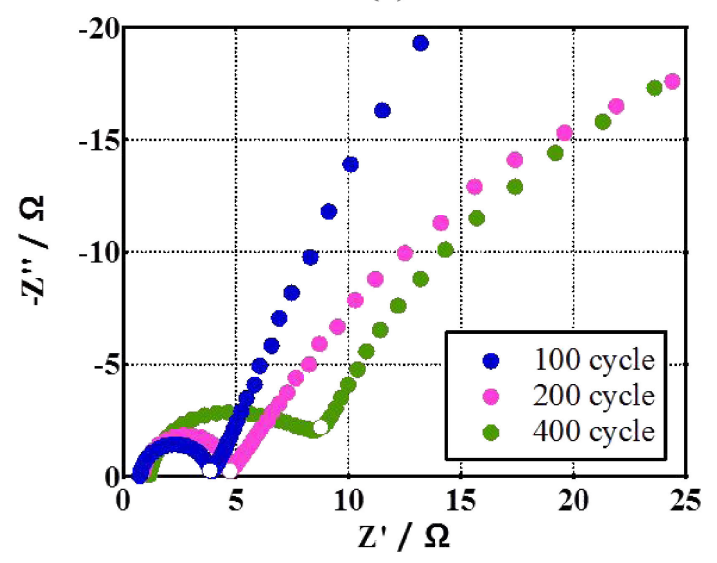

Figure 4. (1) Nyquist plots and (2) magnified Nyquist plots of the laminate cell at open circuit voltage around $3.2 \mathrm{~V}$ after charging process at 100th, 200th and 400th cycle (outline circle: $100 \mathrm{~Hz}$ ).

\section{Conclusion}

In the lithium metal rechargeable battery, the films consisting of the decomposition products (e.g. Li-containing organic compounds, $\mathrm{LiF}$ and $-\mathrm{PO}_{4}$ in the present work) are formed due to the side reaction of freshly deposited lithium metal and electrolyte, and the films are accumulated on the surface of the lithium metal anode during long-term charge/discharge cycles. The accumulation of the films leads to increase the lithium ion transport resistance and the internal resistance of the battery. As a result, the dissolution and deposition reaction of lithium are inhibited and the cell capacity is deteriorated. Inhibiting decomposition reactions of the electrolyte and controlling accumulation of the film are considered to be very effective for the improvement of the cycle performance of lithium metal rechargeable batteries. Therefore, it is necessary to search for efficient factors for each cycle (e.g. the type of electrolyte, additives or how to charge and discharge).

\section{Supporting Information}

The Supporting Information is available on the website at DOI: https://doi.org/10.5796/electrochemistry.18-00080.

\section{Acknowledgments}

This work was supported by Advanced Low Carbon Technology Research and Development Program - Specially Promoted Research for Innovative Next Generation Batteries - (ALCA-SPRING) from
Japan Science and Technology Agency (JST). The XPS measurements, the cross sectional SEM observation and the XRD measurement were carried out at National Institute for Materials Science (NIMS) Battery Research Platform. We would like to thank M. Yanagidate for her help for the XRD measurement at NIMS Battery Research Platform.

\section{References}

1. J. Vetter, P. Novák, M. R. Wagner, C. Veit, K. C. Möller, J. O. Besenhard, M. Winter, M. Wohlfahrt-Mehrens, C. Vogler, and A. Hammouche, J. Power Sources, 147, 269 (2005).

2. S. Zhang, M. S. Ding, K. Xu, J. Allen, and T. R. Jow, Electrochem. Solid-State Lett., 4, A206 (2001).

3. E. Peled, J. Electrochem. Soc., 126, 2047 (1979).

4. D. Aurbach, E. Zinigrad, Y. Cohen, and H. Teller, Solid State Ionics, 148, 405 (2002).

5. D. Aurbach, J. Power Sources, 89, 206 (2000).

6. K. Kanamura, S. Shiraishi, H. Tamura, and Z. Takehara, J. Electrochem. Soc., 141, 2379 (1994).

7. K. Kanamura, H. Takezawa, S. Shiraishi, and Z. Takehara, J. Electrochem. Soc., 144, 1900 (1997).

8. S. Shiraishi, K. Kanamura, and Z. Takehara, Langmuir, 13, 3542 (1997).

9. X. Q. Zhang, X. B. Cheng, X. Chen, C. Yan, and Q. Zhang, Adv. Funct. Mater., 27, 1 (2017).

10. S. Jurng, Z. L. Brown, J. Kim, and B. L. Lucht, Energy Environ. Sci, 11, 2600 (2018).

11. B. Wu, J. Lochala, T. Taverne, and J. Xiao, Nano Energy, 40, 34 (2017).

12. J. Qian, W. A. Henderson, W. Xu, P. Bhattacharya, M. Engelhard, O. Borodin, and J. Zhang, Nat. Commun., 6, 1 (2015).

13. H. Munakata, M. Kotobuki, K. Sasajima, Y. Yamamoto, and K. Kanamura, The 15th International Meeting on Lithium Batteries-IMLB, Abstr., p. 180 (2010).

14. K. Sasajima, Y. Yamamoto, H. Munakata, and K. Kanamura, 217th ECS Meeting, Abstr., p. 356 (2010).

15. K. Kanamura, K. Miyahara, Y. Aoyama, K. Ouchi, M. Haibara, and H. Munakata, 228th ECS Meeting, Abstr., p. 734 (2015).

16. K. Miyahara, Y. Jin, H. Munakata, and K. Kanamura, Honolulu PRiME 2012, Abstr., p. 107 (2012).

17. Y. Maeyoshi, H. Munakata, S. Miyamoto, and K. Kanamura, J. Power Sources, 350, 103 (2017).

18. T. Takada, H. Hayakawa, and E. Akiba, J. Solid State Chem., 115, 420 (1995).

19. N. H. Zainol, Z. Osman, N. Kamarulzaman, and R. Rusdi, Ionics (Kiel), 23, 303 (2017).

20. M. Nagasaki, E. Nagahisa, H. Munakata, and K. Kanamura, The 56th Battery Symposium in Japan, Abstr., p. 199 (2015). [in Japanese]

21. M. Nagasaki, K. Nishikawa, T. Masuda, H. Munakata, and K. Kanamura, The 57th Battery Symposium in Japan, Abstra., p. 130 (2016). [in Japanese]

22. H. Munakata, D. Yamamoto, and K. Kanamura, J. Power Sources, 178, 596 (2008).

23. K. Kanamura, S. Shiraishi, H. Takezawa, and Z. Takehara, Chem. Mater, 9, 1797 (1997).

24. Handbook of X-ray Photoelectron Spectroscopy, ULVAC-PHI, Inc.

25. M. Herstedt, A. M. Andersson, H. Rensmo, H. Siegbahn, and K. Edström, Electrochim. Acta, 49, 4939 (2004).

26. A. M. Andersson, A. Henningson, H. Siegbahn, U. Jansson, and K. Edström, J. Power Sources, 119, 522 (2003).

27. H. Ota, Y. Sakata, Y. Otake, K. Shima, M. Ue, and J. Yamaki, J. Electrochem. Soc., 151, A1778 (2004).

28. M. Nie, D. P. Abraham, D. M. Seo, Y. Chen, A. Bose, and B. L. Lucht, J. Phys. Chem. C, 117, 25381 (2013).

29. C. Marino, M. El Kazzi, E. J. Berg, M. He, and C. Villevieille, Chem. Mater, 29, 7151 (2017).

30. C. Wagner, L. Davis, M. Zeller, J. Taylor, R. Raymond, and L. Gale, Surf. Interface Anal., 3, 211 (1981).

31. D. Aurbach, B. Markovsky, A. Shechter, Y. Ein-Eli, and H. Cohen, J. Electrochem. Soc., 143, 3809 (1996).

32. U. Heider, R. Oesten, and M. Jungnitz, J. Power Sources, 81, 119 (1999).

33. P. Verma, P. Maire, and P. Novák, Electrochim. Acta, 55, 6332 (2010).

34. D. Aurbach, J. Power Sources, 119, 497 (2003).

35. T. Li and P. B. Balbuena, Chem. Phys. Lett., 317, 421 (2000).

36. Y. Wang, S. Nakamura, M. Ue, and P. B. Balbuena, J. Am. Chem. Soc., 123, 11708 (2001).

37. S. E. Sloop, J. B. Kerr, and K. Kinoshita, J. Power Sources, 119, 330 (2003).

38. R. Dedryvère, S. Laruelle, S. Grugeon, L. Gireaud, J.-M. Tarascon, and D. Gonbeau, J. Electrochem. Soc., 152, A689 (2005).

39. H. Nara, D. Mukoyama, T. Yokoshima, T. Momma, and T. Osaka, J. Electrochem. Soc., 163, A434 (2016)

40. D. Aurbach, M. D. Levi, E. Levi, H. Teller, B. Markovsky, G. Salitra, U. Heider, and L. Heider, J. Electrochem. Soc., 145, 3024 (1998).

41. B. Markovsky, M. D. Levi, and D. Aurbach, Electrochim. Acta, 43, 2287 (1998). 